\title{
Grid Interconnection of Wind Energy System at Distribution Level Using Intelligence Controller
}

\author{
W. Z. Gandhare' ${ }^{1}$, S. C. Hete ${ }^{2}$ \\ ${ }^{1}$ Principal, Government College of Engineering Amravati, India \\ ${ }^{2}$ Electrical Engineering Department, Government College of Engineering Amravati, India \\ Email: wz_gandhare@yahoo.co.in, Swapnil.hete20@gmail.com
}

Received February, 2013

\begin{abstract}
Wind generation is being increasingly connected at distribution level due to increasing load demand. Permanent magnet synchronous generator (PMSG) is connected to the wind turbine directly. Through the full power control of AC-DC-AC converters, the electrical power is then connected to the power grid. The power conversion circuits are made up of generator-side three phase diode rectifiers, boost converter and the grid-side three bridges and four wire inverters. A boost converter is controlled through an intelligence controller to maintained DC power constant despite of Variable output of PMSG, the grid-connected operation is constructed using the hysteresis current control method. The inverter is controlled to perform following function 1) power converter to inject power generated from RES to the grid, and 2) shunt APF to compensate current unbalance, load current harmonics, load reactive power demand and load neutral current. The model is implemented in MATLAB/ Simulink using sim power system.
\end{abstract}

Keywords: Point of Common Coupling (PCC); Distributed Generation (DG); Intelligence Controller

\section{Introduction}

Electric utilities and end users of electric power are becoming increasingly concerned about meeting the growing energy demand. Seventy five percent of total global energy demand is supplied by the burning of fossil fuels. But increasing air pollution, global warming concerns, diminishing fossil fuels and their increasing cost have made it necessary to look towards renewable sources as a future energy solution. Since the past decade, there has been an enormous interest in many countries on renewable energy for power generation. The market liberalization and government's incentives have further accelerated the renewable energy sector growth. The wind energy is the alternative energy sources. Previously, they were used to supply local loads in remote areas, outside the national grid. Later, they have become some of main sources. The utility is concerned due to the high penetration level of intermittent Wind energy system in distribution systems as it may pose a threat to network in terms of stability, voltage regulation and power-quality (PQ) issues at PCC [1,2].

Direct-driven permanent magnet synchronous generator (PMSG) is widely used in wind-power generating system [7]. The power converter is a key part of the system for the electrical energy fed into the power grid. With the increasing of power capacity and high demand for power quality, the study of topology of high power converters based on multi-level converter is attracting more and more attention.

The non-linear load current harmonics may result in voltage harmonics and can create a serious PQ problem in the power system network. Active power filters (APF) are extensively used to compensate the load current harmonics and load unbalance at distribution level. This results in an additional hardware cost. However, in this paper control method incorporated the features of APF, conventional inverter interfacing WECS with the grid, without any additional hardware cost and intelligence controller for boost converter.

\section{System Description}

The proposed WECS is composed of a direct-drive $3 \phi$ PMG that has its output fed into a $3 \phi$ diode rectifier. The output of the generator-end rectifier is fed into a Artificial neural network controlled dc-dc converter, which supplies the hysteresis current controlled $3 \phi$ VS grid-side inverter. The grid-side inverter supplies its outputs to a $400-\mathrm{V} 50-\mathrm{Hz}$ grid through a Transformer.

The voltage source inverter is a key element of a WECS system as it interfaces the wind energy source to the grid and delivers the generated power. The variable speed wind turbines generate power at variable ac voltage. Thus, the power generated from this needs power conditioning (i.e., $\mathrm{dc} / \mathrm{dc}$ or ac/dc) before connecting on 
dc-link. Figure 1 shows General Scheme of the wind energy conversion system

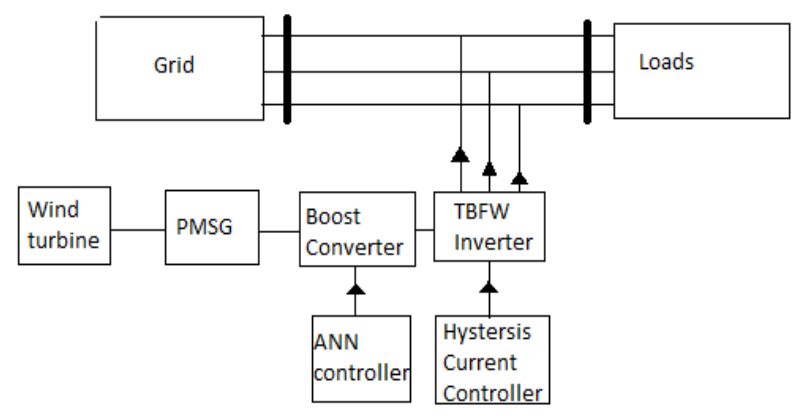

Figure 1. General Scheme of the Wind Energy Conversion System.

\section{Intelligence Controller for Boost \\ Converter}

The control of a dc-dc converter employed in PMG based WECS can be established to achieve the following goals $[3,4]$.

1) To maintain a close-to-fixed dc input voltage to the grid side inverter under wind speed variations as well as under changes in the output power ( $P$ and/or $Q$ ) of the grid-side inverter;

2) To supply energy to the grid-side inverter during transient changes in the wind speed.

The goals of controlling the dc-dc converter can be achieved through adjusting its duty cycle by following formula which regulates the dc output voltage of the generator-end rectifier using artificial intelligence network. Output voltage is step-up and maintained constant using equation

$$
\frac{V_{O}}{V_{i}}=\frac{1}{1-D}
$$

Where,

$\mathrm{V}_{\mathrm{o}}$ - Output voltage of boost converter

$\mathrm{V}_{\mathrm{i} \text { - }}$ Input voltage of boost converter

$\mathrm{D}$ - Duty ratio of boost converter

The duty ratio of the boost converter is varied to compensate the variations in the input voltage. Therefore output voltage is kept at a desired value. Control strategy for closed loop DC-DC boost converter is shown in Figure 2. Here output voltage is sensed and is compared with a set reference voltage. The error is processed through a intelligence controller whose output is used to modulate the pulses that drive the IGBT gate. Gate signals of IGBT are generated by PWM by comparing a carrier signal with the signal generated by intelligence controller. We have developed a feed-forward network which is trained by back propagation algorithm. The simplest way to generate a PWM signal is the interceptive method, which requires only a saw tooth or a triangular waveform and a comparator.

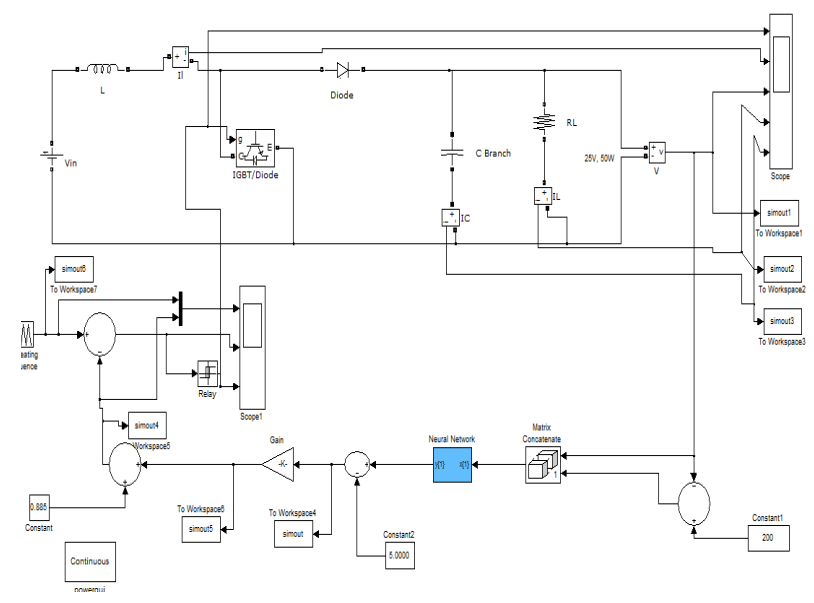

Figure 2. Simulink Model of Boost Converter.

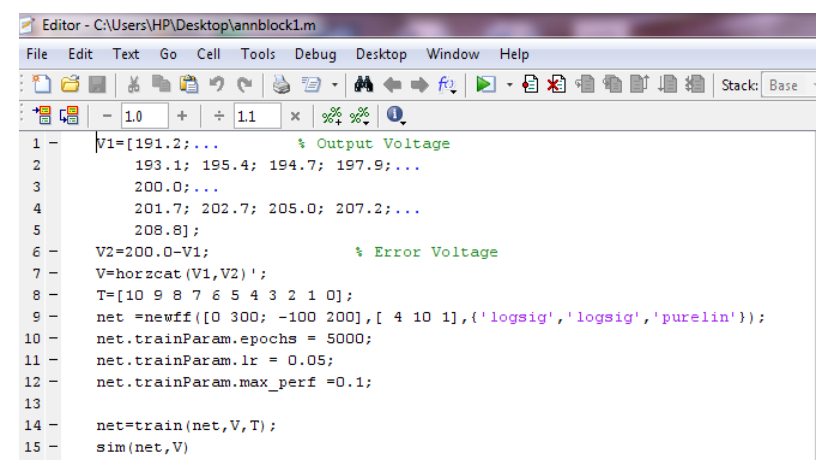

Figure 3. Programme to develop feed-forward network in MATLAB.

When the value of the reference signal is more than the modulation waveform, the PWM signal is in the high state, otherwise it is in the low state [5]. Figure 3. Shows programmed to develop Feed forward network in MATLAB

\section{Control of Grid Interfacing Inverter}

TBFW inverter incorporates the features of APF in the conventional interfacing inverter. The inverter can perform the following functions:

1) Transfer of active power from the generator to the load/grid

2) Reactive power demand support

3) Current unbalance, current harmonics compensation

With adequate control of grid-interfacing inverter, all the objectives can be accomplished either individually or simultaneously. The Power quality constraints can therefore be strictly maintained within the utility standards 
without additional hardware cost.

The DC-link voltage carries the information regarding the exchange of active power in between PMG and grid. Thus the output of DC-link voltage regulator results in an active current. The multiplication of active current component with unity grid voltage vector templates (Ua, $\mathrm{Ub}$ and Uc) generates the reference grid currents ( $\mathrm{Ia}^{*}, \mathrm{Ib}^{*}$ and Ic*). The grid synchronizing angle obtained from phase locked loop (PLL) is used to generate unity vector template.

$$
\begin{gathered}
\mathrm{Ua}=\operatorname{Sin} \theta \\
\mathrm{Ub}=\operatorname{Sin}(\theta-2 \pi / 3) \\
\mathrm{Uc}=\operatorname{Sin}(\theta+2 \pi / 3)
\end{gathered}
$$

The actual DC-link voltage is sensed and compared with reference DC-link voltage. The difference of this DC-link voltage and reference DC-link voltage $\left(\mathrm{Vdc}^{*}\right)$ is given to a discrete-PI regulator to maintain a constant DC-link voltage. The output of the discrete-PI regulator is $\mathrm{Im}$. The instantaneous values of reference three phase grid currents are computed as

$$
\begin{aligned}
& \mathrm{Ia}_{\mathrm{a}}^{*}=\mathrm{Im} \cdot \mathrm{Ua}_{\mathrm{a}} \\
& \mathrm{Ib}^{*}=\mathrm{Im} \cdot \mathrm{Ub}_{\mathrm{b}} \\
& \mathrm{I}_{\mathrm{c}} * \mathrm{Im} \cdot \mathrm{U}_{\mathrm{c}}
\end{aligned}
$$

The reference grid currents (Ia*, $\mathrm{Ib}^{*}$ and $\mathrm{Ic}^{*}$ ) are compared with actual grid currents (Ia, Ib and Ic) to compute the current errors which are given to the hysteresis current controller. The hysteresis controller then generates the switching pulses (P1 to P6) for the gate terminals of grid-interfacing inverter [6].

The switching pattern of each IGBT inside inverter can be formulated on the basis of error between actual and reference current of inverter, which can be explained as:

If $I_{\text {inva }} \geq\left(I_{\text {inva }}-h_{b}\right)$ then upper switch $S_{1}$ will be OFF $\left(P_{1}=0\right)$ and lower switch $S_{4}$ will be ON $\left(P_{a}=1\right)$ in the phase "a" leg of inverter.

If $I_{\text {inva }} \leq\left(I_{\text {inva }}-h_{b}\right)$ then upper switch $S_{1}$ will be ON $\left(P_{1}=1\right)$ and lower switch $S_{4}$ will be OFF $\left(P_{4}=0\right)$ in the phase "a" leg of inverter.

\section{Simulation Model of WTG System}

Figure 4 shows complete model of WTG system, which is implemented in the MATLAB/Simulink Sim Power System library. The Wind Turbine Generation (WTG) system takes wind speed and angular speed of PMSM as input. The torque output of the wind turbine is given as an input mechanical torque for the PMSG. The direction of torque is positive during motoring mode and made negative during generating mode of PMSG. Boost converter is controlled through the intelligence controller and Grid side converter is controlled through hysteresis current control method. The switching pattern of each IGBT inside inverter can be formulated on the basis of error between actual and reference current of inverter.

\section{Simulation Result}

The simulation of the proposed system is done by using MATLAB/Simulink with referring to the control strategy shown in Figure 4. The simulation is done for $4.5 \mathrm{KW}$ system. The output voltage of boost converter is represent in Figure 5. Which demonstrate that the effectiveness of proposed intelligence controller. The output voltage of boost converter is perfectly constant Equal to $400 \mathrm{~V}$.

The TBFW inverter connected to a 3 phase network can be effectively controlled by using hysteresis controller. The TBFW inverter is actively controlled to achieve sinusoidal grid currents despite highly unbalanced nonlinear load. WPG with variable output is connected on the dc link of grid interfacing inverter. Simulation is performed on a three phase balanced non-linear load which consists of a three phase diode rectifier supplying DC voltage to an R-L load. Table 1 gives the specification of various system parameters.

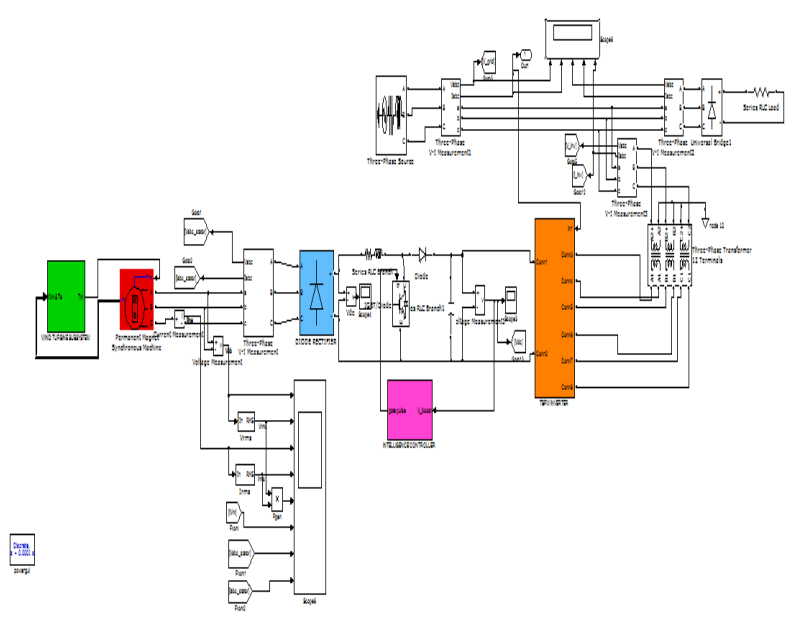

Figure 4. Model of WECS Connected to Grid in SIMULINK.

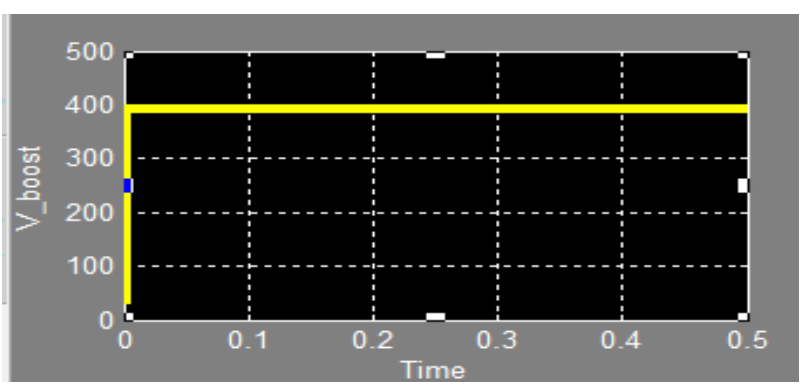

Figure 5. Boost converter output. 
Table 1. System parameters.

\begin{tabular}{ll}
\hline PI Controller & $\mathrm{Kp}=0, \mathrm{Ki}=1$, Sample time 100e-6 \\
\hline Three phase voltage source & Voltage $=400 \mathrm{~V}, \mathrm{Fn}=50 \mathrm{~Hz}$ \\
Series RLC load & $\mathrm{Vn}=1000 \mathrm{~V}, \mathrm{Pn}=1000 \mathrm{~W}, \mathrm{QL}=100 \mathrm{VAR}$ \\
DC voltage & $\mathrm{Vdc}=400 \mathrm{~V}$ \\
Three phase transformer & $\mathrm{P}=10 \mathrm{MVA}, \mathrm{Fn}=50 \mathrm{~Hz}, \mathrm{Rm}=200 \mathrm{pu}$, \\
& $\mathrm{Xm}=200 \mathrm{pu}$ \\
\hline
\end{tabular}

\subsection{When WECS is Not Connected to Grid}

Initially the grid interfacing inverter is not connected to the network. The waveforms of grid currents, load currents and inverter currents are shown in Figure 6. At this time the grid current profile is identical to the load current profile because the load power demand is supplied by grid alone.

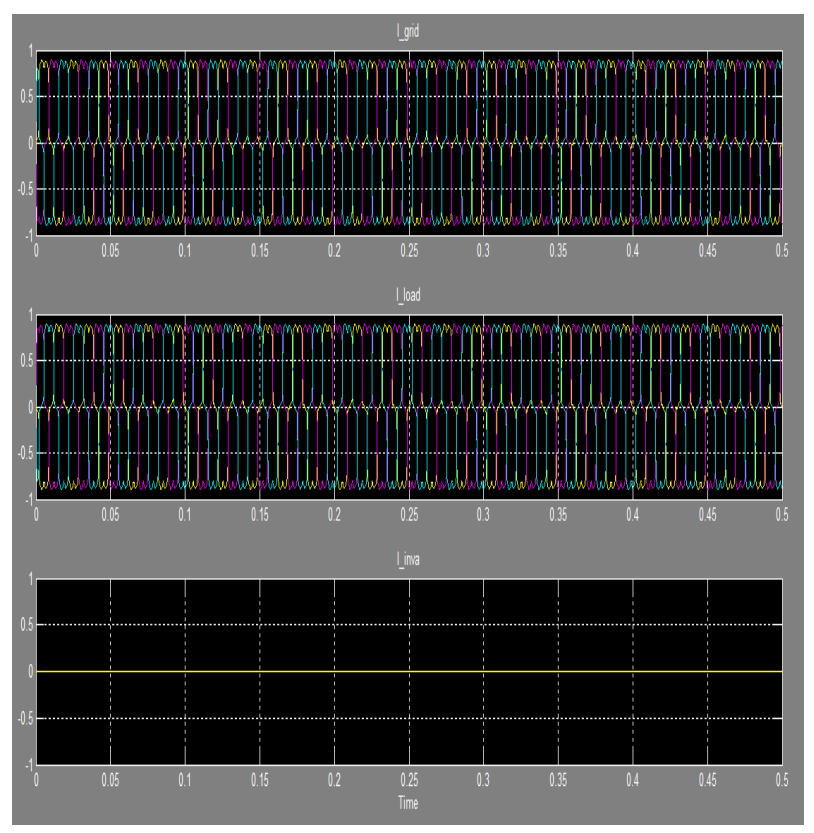

Figure 6. WECS Not connected to grid.

The waveform of grid current, load current and inverter current represented by 'Y-axis' and by 'X- axis' are shown in Figure 6.

\subsection{When WECS is Connected to Grid}

When inverter is connected to the network it starts injecting the current in such a way that the grid current profile changes from unbalanced non-linear to balanced sinusoidal as shown in Figure 7.

Figure 7 shows waveform of grid current, load current and inverter current represented by ' $\mathrm{X}$-axis' and time on
'Y-axis' for when inverter connected to grid.

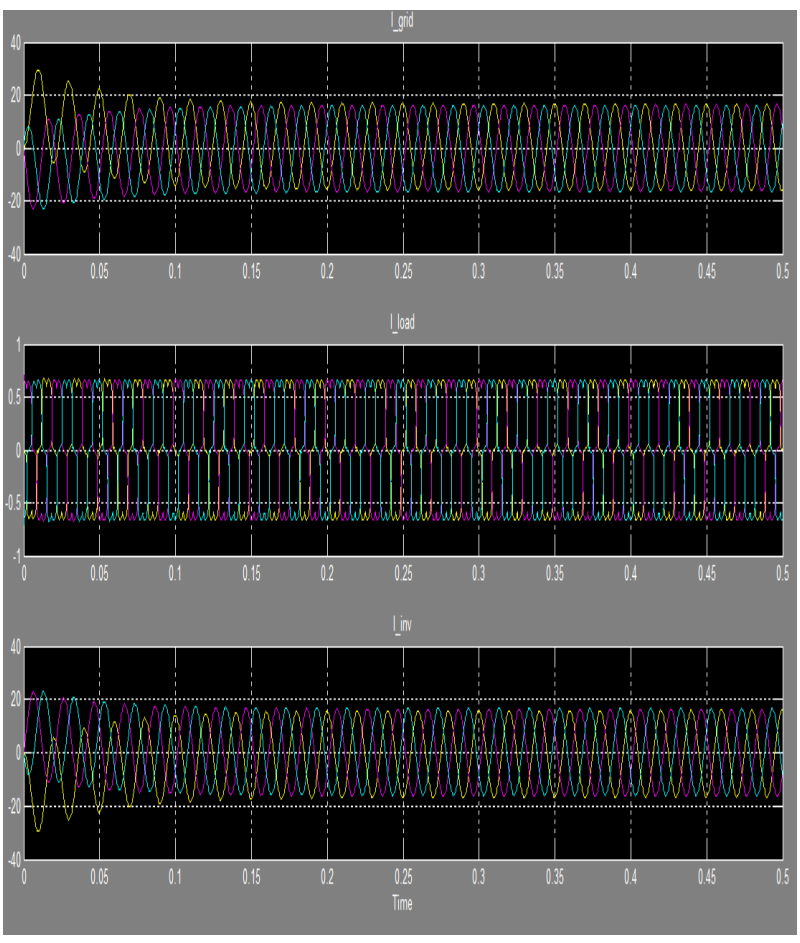

Figure 7. WECS connected to grid.

\section{Conclusions}

The direct drive variable-speed grid-connected PMG based WECS has been simulated. A simple Artificial intelligence controller for boost converter is designed to maintain the constant output voltage of three phase diode rectifier despite the variable output of PMSG. The intelligence controller is able to change the DC output voltage of diode rectifier to constant value under changes in the wind speed and changes in power delivered to the grid. The grid side inverter is controlled using hysteresis current controller which can be utilized to:

1) Inject real power generated from WES to grid and/or

2) Operate as shunt active power filter (APF)

This control method eliminates the need for additional power conditioning equipment to improve the quality of power at PCC.

\section{REFERENCES}

[1] M. Singh and A. Chandra, "Power Maximization and Voltage Sag/swell Ride-through Capability of Permenent Magnet Synchronous Generator Based Variable Speed Wind Energy Conversion System," in Proceeding of IEEE 34th Anual Conf. Indus. Electron. Soc., 2008, pp. 2206-2211. 
[2] B. Renders, K. De Gusseme, W. R. Ryckaert, K. Stockman, L. Vandevelde and M. H. J. Bollen, "Distributed Generation for Mitigating Voltage Dips in Low-voltage Distribution Grids," IEEE Transactions on Power Delivery, Vol. 23, No. 3, 2008, pp. 1581-1588. doi:10.1109/TPWRD.2007.916162

[3] M. E. Haque, M. Negnevitsky, and K. M. Muttaqi, “A Novel Control Strategy for a Variable-speed Wind Turbine with a Permanent-magnet Synchronous Generator,” IEEE Transactions on Industry Applications, Vol. 46, No. 1, 2010, pp. 331-339. doi:10.1109/TIA.2009.2036550

[4] R. Teodorescu and F. Blaabjerg, "Flexible Control of Small Wind Turbines with Grid Failure Detection Operating in Stand-alone and Grid-connected Mode," IEEE
Transactions on Power Electronics, Vol. 19, No. 5, 2004, pp. 1323- 1332. doi:10.1109/TPEL.2004.833452

[5] S. J. jawahar and N. S. Marimuthu, "An Intelligence Controller for Power Electronics Boost Converter," International Journal of Soft Computer, Vol. 3, 2008, pp. 69-73.

[6] P.C.Thomas, et al., "A Novel Wind Energy Conversion System with Power quality Improvement Feature,” IEEE PES Innovative Smart Grid Technologies, 2011, pp. 1-4.

[7] S. Song, S. Kang and N. Hahm, "Implementation and Control of Grid Connected AC-DC-AC Power Converter for Variable Speed Wind Energy Conversion System," IEEE Conference and Exposition Applied Power Electronics, Vol. 1, 2003, pp. 154 -158. 